\title{
The FREE (Firm Resources and External Environment) Framework as an Alternative to SWOT: An Abstract
}

\author{
Sreedhar Madhavaram, Shelby D. Hunt, and Pelin Bicen
}

\begin{abstract}
For more than five decades, SWOT analysis has remained popular with business and marketing strategy educators and practitioners. However, it also attracts severe criticisms from business and marketing strategy academics and practitioners. In fact, some recommendations call for abandoning the use of SWOT for analysis. In this research, we review the literature on SWOT to delineate advantages or uses, disadvantages or concerns, and recommendations or recommended alternatives. On the foundations resource-based (R-B) strategy and resource-advantage (R-A) theory, we introduce a new framework that can be viewed as an alternative to the SWOT framework. The FREE (Firm Resources and External Environment) framework requires analysis in two parts: analyzing the firm's resources and analyzing the external environment using the five environmental factors (the societal resources on which firms draw, the societal institutions that frame the rules of the game, the actions of competitors, the behaviors of consumers and suppliers, and public policy decisions). A discussion of the advantages of FREE framework over the SWOT framework is provided.
\end{abstract}

References Available Upon Request

\author{
S. Madhavaram ( $\square)$ \\ Cleveland State University, Cleveland, OH, USA \\ e-mail: s.madvaram@csuohio.edu \\ S.D. Hunt \\ Texas Tech University, Lubbock, TX, USA \\ e-mail: shelby.hunt@ttu.edu \\ P. Bicen \\ Suffolk University, Boston, MA, USA \\ e-mail: pbicen@suffolk.edu
}

